\title{
Aves em liberdade: solte essa ideia!: relato de açóes extensionistas voltadas para a preservaçáo ambiental
}

\author{
Birds in freedom: release this idea!: report of extension for environmental \\ preservation
}

\section{RESUMO}

Dentre os animais silvestres, as aves são as mais visadas pelo tráfico, sendo também preferidas para a criação doméstica. Este trabalho teve como objetivo a sensibilização do público participante quanto à importância das aves livres para o equilíbrio dos ecossistemas, a fim de propiciar o fortalecimento dos aspectos éticos, científicos e sociais dos envolvidos frente ao costume de se comercializar e aprisionar aves silvestres em gaiolas. As atividades do projeto, que tiveram como foco os municípios de Santo Antônio do Monte e Divinópolis - MG, constaram principalmente de: a) exposições fotográficas de aves da região; b) palestras em escolas públicas; c) concurso de desenho para estudantes. Teve como público alvo estudantes da rede pública, docentes e discentes da Universidade do Estado de Minas Gerais - UEMG, Unidade Divinópolis e ainda, pessoas interessadas pelo assunto. As atividades contaram com um público total de 1.167 visitantes nas exposiçóes fotográficas, 430 estudantes nas palestras e 1.023 participantes no concurso de desenho. A metodologia utilizada e as informaçóes repassadas durante as atividades permitiram atingir os objetivos propostos, interagindo positivamente junto ao público participante, que de modo geral mostrou relevante interesse pelas temáticas trabalhadas, assim como nítida sensibilização frente à problemática do tráfico e engaiolamento de aves silvestres.

Palavras-chave: Avifauna. Educação ambiental. Tráfico de animais silvestres. Meio ambiente.

\begin{abstract}
Among the wild animals, birds are the most targeted by traffic, being also preferred for domestic creation. The objective of this work was to raise the public awareness on the importance of free birds for the balance of ecosystems in order to provide the strengthening of the ethical, scientific and social aspects of those involved in the practice of commercializing and imprisoning wild birds in cages. The activities of
\end{abstract}

Alysson Rodrigo Fonseca

Doutorado em Ciências (Entomologia) pela Universidade Federal de Lavras, Minas Gerais, Brasil; professor pesquisador da Universidade do Estado de Minas Gerais, Unidade Divinópolis, Brasil. (arodrigofonseca@hotmail.com).

Carolina Corrêa de Menezes

Graduanda em Ciências Biológicas pela Universidade do Estado de Minas Gerais, Unidade Divinópolis, Brasil; bolsista do Programa de Apoio à Extensão (PAEX/ UEMG) (carol.ccm2@gmail.com).

Clécio Eustáquio Gomides

Mestre em Saneamento, Meio Ambiente e Recursos Hídricos pela Universidade Federal de Minas Gerais, Brasil; professor pesquisador da Universidade do Estado de Minas Gerais, Unidade Divinópolis, Brasil. (clecio.gomides@uemg.br).

Daniel Silva Santos

Graduado em Engenharia Civil (Meio Ambiente) pela Universidade do Estado de Minas Gerais, Brasil; membro do Grupo de Observadores de Aves de Santo Antônio do Monte, Minas Gerais, Brasil. (daniel@planejarengenharia.com). 
the project, which focused on the municipalities of Santo Antônio do Monte and Divinópolis - MG, consisted mainly of: a) photographic exhibition of birds from the region; b) lectures in public schools; c) drawing contest for students. The work had as a target public school students and the teachers and students of the Minas Gerais State University - UEMG, Divinópolis Unit and people interested in the subject. The activities had a total audience of 1,167 visitors in the photographic exhibitions, 430 students in the lectures and 1,023 participants in the drawing competition. The methodology used and the information passed during the activities allowed to reach the proposed objectives, interacting positively with the participating public, who showed a relevant interest in the topics studied, as well as a clear awareness of the problems of trafficking and entailment of wild birds

Keywords: Bird fauna. Environmental education. Trafficking of wild animals. environment.

\section{INTRODUÇÃO}

De maneira geral, a fauna é considerada como uma verdadeira riqueza para a humanidade, por seu notável valor ecológico, científico, econômico e cultural. Lamentavelmente, uma parcela considerável da sociedade não reconhece, de forma condigna, a magnitude desses valores. Nesse sentido, grande parte da população e dos governantes não têm consciência do valor ecológico que as espécies da fauna desempenham na estruturação e manutenção dos ecossistemas, e que depende delas o equilíbrio biológico essencial para todas as formas de vida (VIDOLIN et al., 2004).

São inúmeros os fatores que ocasionam prejuízos à fauna silvestre, sendo muitos deles de caráter irreversível. A busca de desenvolvimento econômico, por meio industrial, agrícola ou florestal está entre os principais fatores de pressão sobre as áreas naturais e, consequentemente, sobre as espécies da fauna (VIDOLIN et al., 2004). Aliado a esse fator, o tráfico de animais silvestres é o terceiro maior comércio ilegal do mundo, perdendo apenas para o tráfico de drogas e de armas. O Brasil participa desse mercado com aproximadamente US\$ 1 bilhão ao ano, uma vez que sua rica biodiversidade, os problemas sociais e as razóes 
culturais fazem do Brasil um dos principais fornecedores de animais silvestres do mundo (GIOVANINI, 2002).

Em Minas Gerais, a regiáo Centro-Oeste, onde estão localizados os dois municípios em que esse projeto foi executado (Divinópolis e Santo Antônio do Monte), é considerada, entre as nove regiôes do Estado, a quarta com maior número de ocorrências relativas à criação e ao transporte de animais silvestres sem licença, perdendo apenas para a regióes do Vale do Rio Doce; Metropolitana de Belo Horizonte e Zona da Mata (HAMADA, 2004).

Dentre os animais traficados, as aves por sua beleza e pelos seus cantos, ampla distribuição geográfica e alta diversidade (PEREIRA; BRITO, 2005), aliado aos aspectos culturais historicamente deixados pelos índios e colonizadores, constituem-se no grupo de animais mais procurados. Mesmo antes da descoberta do Brasil pelos portugueses, as aves brasileiras têm sofrido pressão sobre sua caça e captura pelos índios, sendo esses hábitos impulsionados pelos colonizadores, os quais começaram a capturar, além das espécies já caçadas e criadas como animais de estimação pelos indígenas, exemplares que os atraíam pela beleza e qualidade do canto (SILVEIRA; MÉNDEZ, 1999). Como herança desse hábito, infelizmente ainda é fator corriqueiro da cultura brasileira o aprisionamento de aves em gaiolas, impulsionado pelo tráfico ilegal e pela grande diversidade. Tais fatores contribuem para que as aves estejam entre os animais mais cobiçados como animais de estimação (NUNES; BARRETO; FRACO, 2012).

Sendo um hobby ou simplesmente como fonte de renda, milhares de animais são mantidos confinados em viveiros e gaiolas em todo o país (HERNANDEZ; CARVALHO, 2006), sendo que a maior parte dessa criação ocorre de forma criminosa e contrária às leis de proteção de Fauna e Flora (Lei no . 9.605/98 e o Decreto no ${ }^{\circ}$ 6.514/08), podendo a pessoa que pratica essa intervenção ser autuada, pagar multa e responder criminalmente pela infração.

Do ponto de vista ecológico, o impacto mais significativo gerado pelo tráfico de animais é o desequilíbrio populacional, já que a captura excessiva é a segunda principal causa da redução populacional de várias espécies, perdendo apenas para a degradação e perda de habitat provocada pelo desmatamento (MARINI; GARCIA, 2005). Além disso, o pássaro preso é excluído do processo reprodutivo e de seu papel 
ecológico específico, ficando incapacitado de deixar descendentes e interagir com outras espécies, o que aumenta o risco de extinção (SICK, 1997).

Importante também ressaltar que, no caso de aves que são capturadas nos ambientes naturais e trazidas para dentro das residências, há o risco iminente de serem reservatórios e disseminadoras de doenças (zoonoses) que podem afetar os animais domésticos e inclusive as pessoas (BARBOSA; MARTINS; MAGALHÂES, 2011). Paralelamente a esses aspectos mencionados, devemos ainda considerar o fator ético, ou seja, que direitos tem o ser humano de aprisionar perpetuamente um ser vivo voante em uma gaiola apenas para satisfazer seus desejos pessoais? Segundo Prohnii et al. (2017), é imoral que os animais arquem com a privaçáo da sua liberdade, vida social e com o seu sofrimento para que o homem possa usufruir de alguns momentos agradáveis.

Como uma forma alcançável de se buscar uma reversão para este lamentável quadro, Rocha (2010) propõe a conscientização das pessoas através da educação ambiental, na qual os recursos da biodiversidade devem ser vistos e compreendidos como um valor perene, fonte de equilíbrio ecológico, alegria, beleza e identidade (ROCHA, 2010). O processo educativo deve voltar-se para a transformaçáo cultural e ética do homem. Dessa forma, urge sensibilizar as pessoas contra a captura, o tráfico e a manutenção em cativeiro de animais silvestres, e sobre os maus tratos que lhes são impostos - a educação precisa cultivar um ser humano terno e capaz de se emocionar com a beleza, de respeitar o outro, seja este uma pessoa, um animal, uma planta, a natureza, o próprio mundo, a Terra (GONÇALVES; REGALADO, 2007). Aliado a isso, deve também contribuir para que os sujeitos compreendam o papel dos seres vivos no ambiente e os impactos que a caça e aprisionamento desses animais podem provocar, bem como as consequências dessas açôes para o próprio ser humano.

Por fim, conforme afirma Gonçalves e Regalado (2007) e Rocha (2010), um dos grandes desafios da contemporaneidade seria relativo à mudança de atitude quando se trata da interaçáo com os elementos da natureza, através de uma consciência clara e ética quanto ao uso e ocupaçáo do meio natural e os organismos que ali vivem e interagem. Para tanto, torna-se necessário que as informaçôes visem despertar 
no homem reflexóes que resultem em mudança de atitudes e hábitos, sendo que é nessa perspectiva que esse projeto se fundamenta.

A partir desse contexto e buscando contribuir para a minimização desse problema socioambiental, o tráfico e o aprisionamento de pássaros em gaiolas, este texto tem como objetivo apresentar as açóes e resultados referentes ao projeto "Aves em liberdade: solte essa ideia!", trabalho que visou executar açóes focadas na sensibilização e educação ambiental, nos municípios de Santo Antônio do Monte ${ }^{1}$ e Divinópolis ${ }^{2}$, ambos localizados na região Centro-Oeste de Minas Gerais.

Por fim, cabe ressaltar que o projeto, foco desse artigo, alinha-se com o Programa Institucional de Extensão da Universidade do Estado de Minas Gerais (UEMG) "Cultura e Desenvolvimento", ao propor a capacitação e o desenvolvimento de ações voltadas para as dimensões social, ambiental e cultural da sustentabilidade e, ainda, com o Plano Nacional de Extensão Universitária, na medida em que propicia o diálogo entre a universidade, prefeitura e a iniciativa privada e insere a educação ambiental e o desenvolvimento sustentável como componentes da atividade extensionista.

A proposta teve como objetivo principal a sensibilização ambiental do público participante quanto à importância das aves livres para o equilíbrio dos ecossistemas, a fim de propiciar o fortalecimento dos aspectos éticos, científicos e sociais dos envolvidos. Buscou, ainda, capacitar o público em relação aos aspectos negativos da prática de captura, comercialização e aprisionamento de aves silvestres; fomentar a prática de observação de aves como instrumento de educação e preservaçáo ambiental; e, por fim, propiciar conhecimentos ecológico/ científicos, de forma a fortalecer o aspecto conservacionista do públicoalvo, capacitando-os para que sejam elementos transformadores da realidade.

\section{METODOLOGIA}

O projeto, iniciado em fevereiro de 2017 e finalizado em dezembro desse mesmo ano, teve como público-alvo alunos, professores e familiares de escolas públicas de Santo Antônio do Monte e
O município conta com uma área de $1.125,780 \mathrm{~km}^{2}$ e populaçáo estimada de 27.352 habitantes. Na rede pública de ensino, conta com 4.727 alunos matriculados em todos os níveis, totalizando 18 escolas (IBGE, 2018).

Possui uma área de $716 \mathrm{~km}^{2} \mathrm{e}$ populaçáo estimada de 234.937 habitantes. Conta atualmente com 32.730 estudantes matriculados em todos os níveis de ensino da rede pública, em um montante de 90 escolas (IBGE, 2018). 
Divinópolis e, ainda, a comunidade acadêmica da UEMG, Unidade Divinópolis. Entretanto, puderam participar também todos os sujeitos que, mesmo não se enquadrando nesses grupos, tiveram interesse pelo assunto.

Dentre as atividades propostas, a exposição fotográfica denominada "Aves dos Montes" teve como objetivo mostrar parte da diversidade de aves da região Centro-Oeste de Minas Gerais, em especial as do município de Santo Antônio do Monte, por meio de registros feitos pelos proponentes deste trabalho. Assim, buscou sensibilizar o público quanto à beleza, variedade e importância desses animais livres. Para a divulgação dessa exposiçáo e atividades relacionadas, foram elaborados, em fevereiro de 2017 , pela própria equipe organizadora do evento, dois modelos de cartazes $(80 \times 60 \mathrm{~cm})$ e um de filipetas $(10 \times 21 \mathrm{~cm})$, sendo reproduzidas 90 e 2.500 cópias, respectivamente. Visando atingir o público-alvo e demais pessoas interessadas, esses materiais foram encaminhados para escolas, faculdades e universidades de Santo Antônio do Monte, Divinópolis e cidades da região, além de serem também fixados em estabelecimentos comerciais.

A exposição foi realizada em dois momentos distintos: o primeiro aconteceu em Santo Antônio do Monte, na semana do meio ambiente (3 a 9 de junho de 2017) no Centro Turístico e Cultural e Exposição (CETUC). Uma segunda edição dessa exposição ocorreu em Divinópolis, na unidade da Universidade do Estado de Minas Gerais (UEMG), durante a segunda edição do Seminário de Saúde, Meio Ambiente e Educação, que aconteceu na última semana de novembro de 2017. Em ambos os eventos, o período de visitação foi de $8 \mathrm{~h}$ às $19 \mathrm{~h}$. As fotos foram impressas em PVC, em tamanho $67 \mathrm{x}$ $100 \mathrm{~cm}$, totalizando 32 unidades. Cada foto exposta possuía um QR $\operatorname{code}^{3}$ que redirecionava para o site WikiAves, no qual era possível ouvir o som de cada ave e mais informaçóes dos hábitos e habitats de cada espécie.

Durante a exposição das fotos, esteve sempre presente pelo menos um representante da equipe, com a finalidade de manter a organização do espaço e principalmente, esclarecer dúvidas em relação às aves documentadas nas fotografias, assim como outros assuntos correlacionados, como o tráfico e comércio de animais silvestres, formas de preservação ambiental e a prática da observação e fotografia
${ }^{3}$ Abreviação para Quick Response Code. Tecnologia desenvolvida pela empresa Denso Wave, subsidiária da Toyota. Rapidamente, transformou-se no mais famoso código de barras existente, possibilitando inúmeras potencialidades estratégicas que os códigos oferecem, sendo de fácil obtenção e na maioria das vezes gratuito. Para que seja possível digitalizar um QR Code através de um smartphone é necessário que o dispositivo possua, além de câmera fotográfica, um leitor apropriado para o sistema operacional do aparelho (GABRIEL, 2010). 
de aves. A presença dos alunos e demais interessados nas atividades foi registrada por meio de listas de presença.

Paralelamente à exposição fotográfica, no dia 4 de junho, foi também oferecido no CETUC o minicurso "Fotografando Aves", que teve como objetivo ministrar aos participantes os conhecimentos e técnicas básicas para a fotografia de aves, seguido pela observação guiada em campo. Esta atividade teve duração de seis horas, com três horas de aula teórica pela manhã e três de prática no período da tarde. Para facilitar o encontro com as aves e assim permitir a prática da fotografia, foram instalados, na área verde do CETUC, três comedouros feitos artesanalmente com colmos de bambu e abastecidos com farelo de milho, visando atrair esses animais.

Outra atividade desenvolvida pelo projeto constou de palestras com o tema "A importância das aves em liberdade", que tiveram como objetivo propiciar uma educação ambiental voltada para a sensibilização do público participante quanto à importância das aves livres, abordando os aspectos éticos, científicos e sociais envolvidos nessa temática. Buscou-se, portanto, abordar as principais características do táxon, sua importância ecológica e econômica, os aspectos negativos da prática de captura, comercialização e aprisionamento de aves silvestres e, por fim, nosso papel ético frente aos outros seres vivos.

Em Santo Antônio do Monte as palestras foram ministradas diariamente durante a exposição das fotos no CETUC, de 3 a 9 de junho de 2017, e em todas as sete escolas municipais da rede pública de ensino, entre abril a junho de 2017. Em Divinópolis, ocorreram durante toda a vigência do projeto, em datas variadas entre os meses de junho a setembro de 2017, abrangendo as cinco escolas públicas que participaram do PIBID/UEMG - Programa Institucional de Bolsas de Iniciação à Docência. As palestras tiveram duração de aproximadamente 50 minutos, com outros 20 para discussáo e respostas às dúvidas e questionamentos.

No município de Santo Antônio do Monte foi também proposto um concurso de desenho com o tema "Aves em liberdade: solte essa ideia”. O concurso, aberto a todos os alunos da rede pública municipal de Santo Antônio do Monte que participaram das palestras nas escolas, foi lançado em 4 de abril de 2017, com o encerramento das inscriçôes em 20 de maio desse mesmo ano. O concorrente deveria 
desenhar e colorir uma ave que existe na regiáo, sendo essa informação disponibilizada aos participantes através de uma lista com o nome das aves. O concurso foi dividido por categorias e as 15 melhores ilustraçóes ficaram expostas na mostra de fotografias das aves da regiáo (citada anteriormente), sendo disponibilizados troféus aos ganhadores.

Visando divulgar as atividades propostas e convidar a comunidade a participar, foi criada uma página no Facebook, que se manteve ativa durante toda a vigência do projeto. Várias informaçóes com assuntos correlacionados foram também postadas, visando despertar interesse e propiciar maior interação com seguidores do grupo.

\section{RESULTADOS E DISCUSSÃO}

As exposiçóes das fotos das aves em Santo Antônio do Monte e Divinópolis (Figura 1), contaram com a participação de 727 e 440 visitantes, respectivamente. Nessa atividade, ao contrário das demais em que se verificou a predominância de crianças e jovens estudantes, verificou-se a maior diversificaçáo do público, com a presença de adultos e idosos.

Figura 1 - Exposição fotográfica "Aves dos Montes", em Santo Antônio do Monte e Divinópolis, Minas Gerais

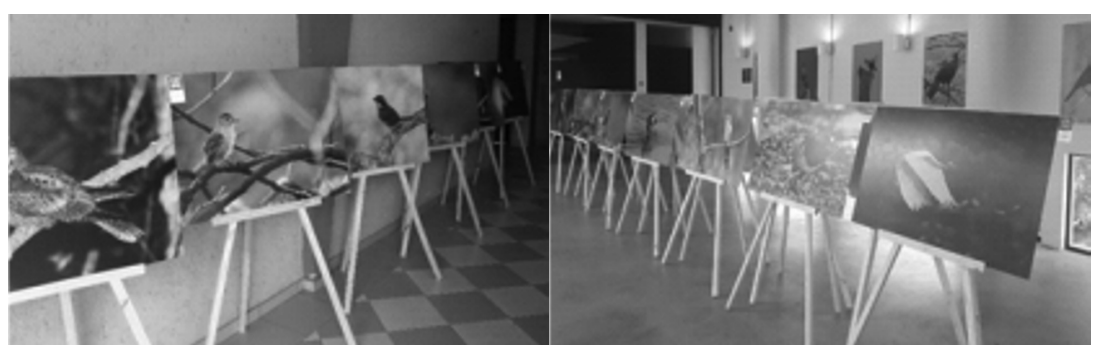

Fonte: Os autores (2017).

Foi notória a "surpresa" de maior parte dos visitantes em relação à diversidade de aves da regiáo mostradas nas fotos que desconheciam a variedade de aves na região. A disponibilidade de um $Q R$ code em cada fotografia permitiu aos visitantes conhecer melhor sobre os hábitos e habitats de cada espécie, assim como o seu "canto", aproximando ainda mais o objeto de seu observador. Portanto, acreditamos que essa exposição foi importante para despertar no público não somente o 
interesse pela avifauna local, mas principalmente conhecimento da riqueza de espécies que a região abriga.

A utilizaçáo da fotografia no processo educativo pode fazer com que a percepçáo da imagem capturada expresse mais do que apenas a sua estética. É possível que a fotografia permita que o sujeito seja conduzido a novas linguagens, inclusive à dimensão política dos fenômenos representados, visto que o conteúdo daquele enquadramento não se traduz em sentidos que impressionam, que causam ruídos na comunicação, mas fornece detalhes que constituem o próprio saber na sua essência (BARTHES, 1984). Ainda segundo o autor, a colocação do significado dessa imagem no processo educativo permite que haja um acesso mútuo aos conhecimentos, e aquilo que o outro me diz contribui para a minha formação. A consideração dos aspectos socioambientais que caracterizam um dado espaço possibilita que conteúdos teóricos sejam abordados a partir de uma referida realidade, mostrando ao outro que a sua participaçáo é mais do que fundamental para a construção desse conhecimento, corroborando o princípio da participação presente na educação ambiental.

Os dois modelos de cartazes desenvolvidos para a divulgação da exposição fotográfica e atividades correlacionadas sấo mostrados na Figura 2. Foi possível verificar que os cartazes tiveram um impacto bastante positivo, pois as fotografias das aves naturalmente evocavam um interesse comum entre os que tinham contato visual com esse material. Muitos se admiram pelo fato das aves mostradas nos cartazes serem encontradas na região, propiciando comentários do tipo "eu já vi essa ave em meu sítio" ou ainda "não acredito que no nosso município temos passarinhos tâo bonitos!”. 
Figura 2 - Modelos de cartazes para a mostra fotográfica "Aves dos Montes"

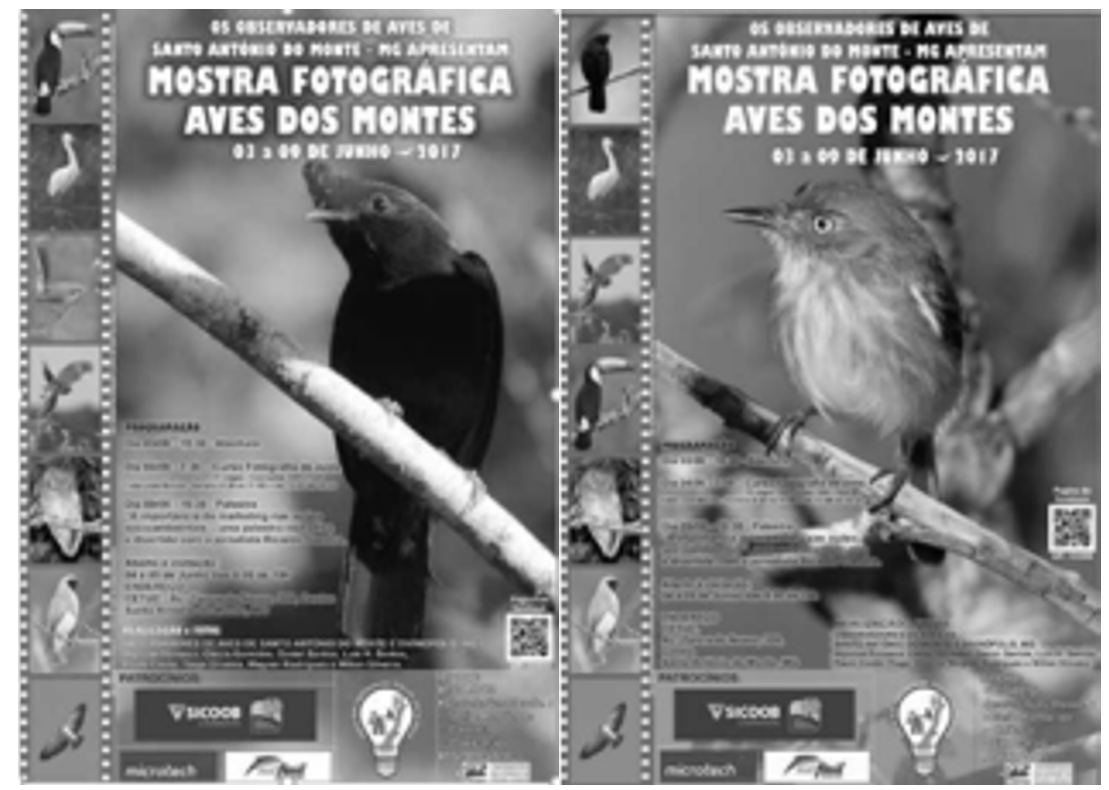

Fonte: Os autores (2017).

O minicurso "Fotografando Aves", realizado concomitantemente à exposição fotográfica, contou com cinco participantes, sendo todos adultos e com idade variando entre 26 a 62 anos. Embora o número de inscritos tenha sido pequeno (possivelmente em função da necessidade de se ter uma máquina fotográfica), verificou-se um grande interesse dos participantes pela fotografia e pelo universo das aves. A montagem de comedouros artesanais de colmos de bambu propiciou a atração de várias espécies de aves, como pardais, canários da terra, rolinhas e papa-capins.

No que se refere às palestras, em Santo Antônio do Monte, contabilizou-se 276 pessoas naquelas realizadas no CETUC, no mesmo período da exposição de fotos. Já nas escolas que participaram do projeto, obteve-se um público total de 592 alunos. Em Divinópolis, as palestras realizadas nas escolas contaram com 190 participantes (Figura 3). 
Figura 3 - Palestras ministradas nas escolas públicas de Santo Antônio do Monte e Divinópolis, Minas Gerais

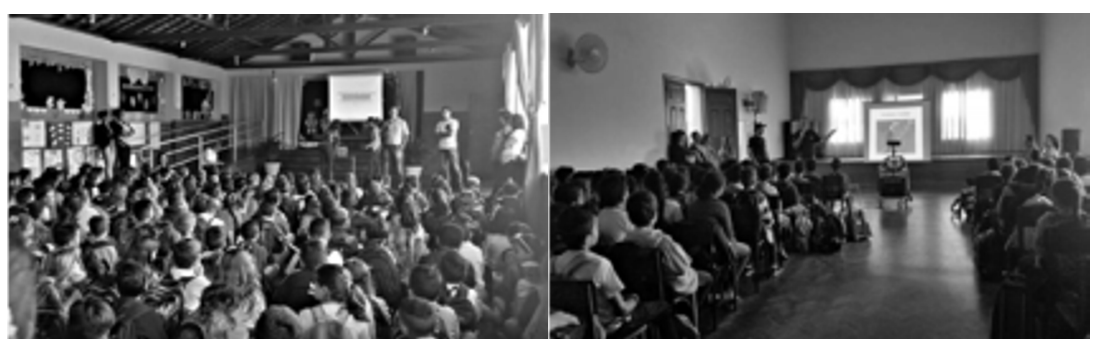

Escola Municipal Amâncio Bernardes. Escola Municipal Prefeito Geraldo Santo Antônio do Monte-MG. Luiz de Castro. Santo Antônio do Monte - MG.

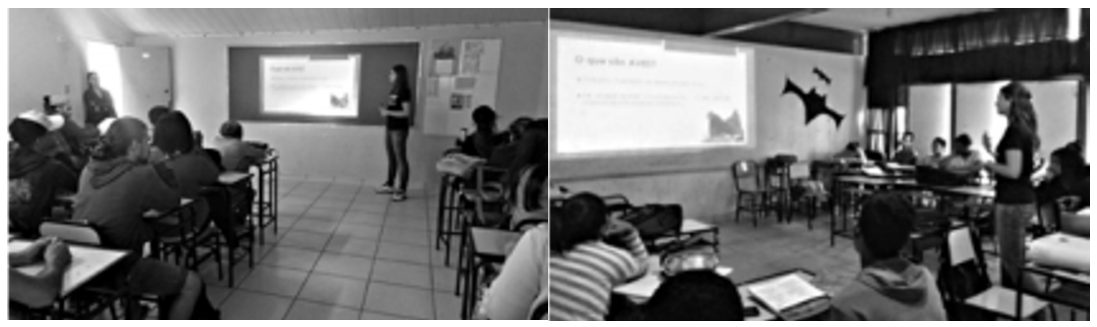

Escola Estadual Patronato Bom Pastor. Escola Estadual São Francisco de Paula. Divinópolis - MG.

Divinópolis - MG.

Fonte: Os autores (2017).

Verificou-se entre o público alvo das palestras, e em especial entre os alunos das escolas públicas, um relevante interesse pelo tema, visto que as aves já fazem parte do cotidiano dessas pessoas, especialmente daquelas que vivem ou convivem no meio rural ou têm pássaros engaiolados nas cidades. Foi também notório que a maioria delas não tinha conhecimentos suficientes para entender a importância ecológica das aves, fato constatado quando lhes foi perguntado informalmente no início das palestras: "Vocês acham as aves importantes? Por quê". Ao final das palestras, a mesma pergunta foi feita novamente, e respostas que relacionavam às aves ao "equilíbrio ecológico", "controle de outros organismos e pragas", "dispersão de sementes", "polinização", "fonte de alimento", "beleza" e "canto" foram frequentes. Os estudantes também interagiram bem com os palestrantes, contando, por exemplo, sobre suas experiências e situaçóes vivenciadas envolvendo as aves, sejam em seus lares, escola, casas de amigos ou vizinhos. Infelizmente, a maior parte dos relatos se referia a pessoas que caçavam e mantinham 
pássaros presos em gaiolas, porém todos, sem exceção, consideravam essa prática como negativa e nociva aos animais e ao meio ambiente.

Cabe ressaltar que após as palestras que aconteceram no CETUC foram doadas ao público interessado mudas de árvores nativas do cerrado, obtidas gratuitamente junto ao Instituto Estadual de Florestas (IEF). Optou-se por esse "brinde" uma vez que nas palestras foi discutido a importância das aves para a manutenção e equilíbrio das florestas e outros tipos de vegetação em ecossistemas naturais.

O concurso de desenho "Aves em liberdade: solte essa ideia", realizado com alunos da rede pública municipal de Santo Antônio do Monte, envolveu um montante de 1.023 participantes. Ele foi dividido por categorias e as melhores ilustraçóes de aves da regiáo (Desenho I) foram expostas na exposiçáo de fotos de aves que ocorreu no CETUC, sendo disponibilizados troféus aos ganhadores e medalhas às professoras de cada aluno.

Desenho 1 - Quatro primeiros desenhos ganhadores do concurso com o tema "Aves em liberdade: solte essa ideia".
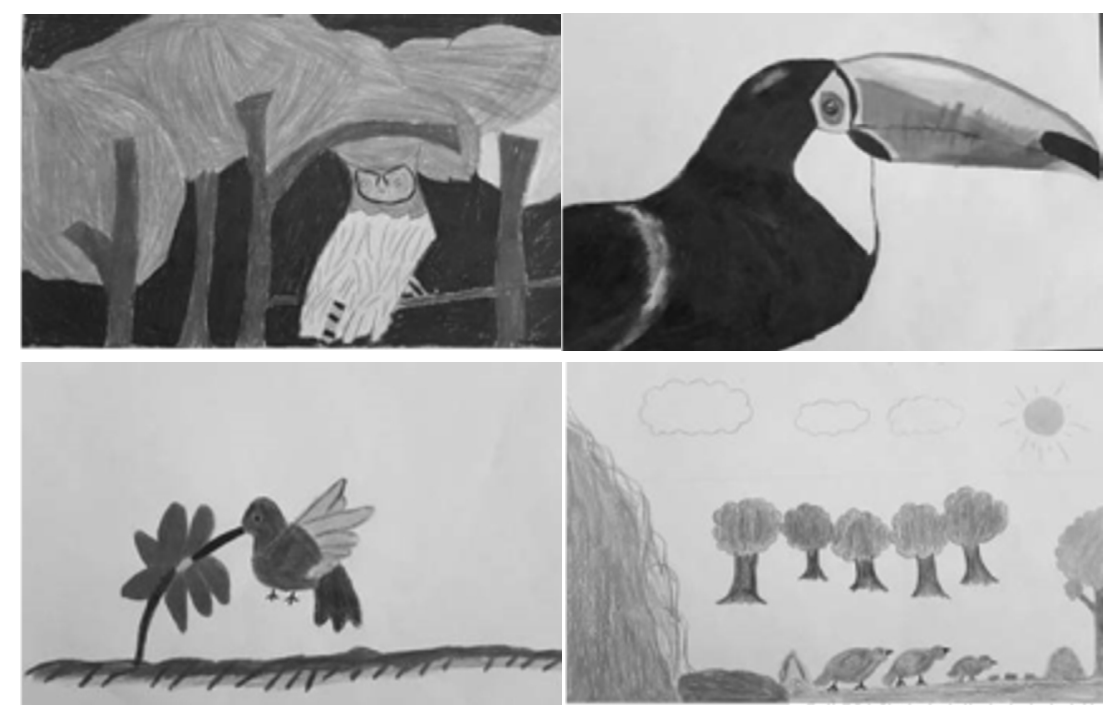

Fonte: Acervo do projeto (2017).

Verificou-se, em todas as etapas dessa atividade, um grande interesse, não somente das crianças, mas também das direçôes das escolas que participaram. Os estudantes, além de praticarem a ludicidade por 
meio do desenho e da pintura, conheceram um pouco das espécies de aves que ocorrem na região, assim como seu papel ecológico, como é o caso do desenho do beija-flor realizando a polinização (Figura 3). Segundo Carvalho (2011), as atividades lúdicas permitem um desenvolvimento mais global e uma visão de mundo mais real, porque é por meio das descobertas e da criatividade que a criança e o adolescente se expressam, analisam, criticam e transformam a realidade. Assim, quando corretamente aplicada e compreendida, essas atividades poderáo contribuir para a melhoria do aprendizado e a qualificação ou formação crítica do educando, redefinindo valores e melhorando o relacionamento das pessoas entre si e o meio do qual fazem parte. Como a educação ambiental, a ludicidade também é um instrumento de sensibilização e emancipação do ser humano, além de extremamente útil na temática ambiental. Behling e Islas (2014) complementam, apontando que, por meio do lúdico, as atividades de educação ambiental auxiliam no desenvolvimento de posturas ambientalmente responsáveis, com o objetivo de apoiar a formação de uma consciência ambiental crítica que leve à transformação de comportamentos.

Sobre a página "Aves dos Montes", criada no Facebook ${ }^{4}$, verificouse, no período de execução do projeto, uma abrangência nacional e internacional, alcançando visualizaçóes por 3.632 pessoas em 35 países, incluindo o Brasil. A página permitiu a divulgação do projeto para a comunidade externa, divulgando e esclarecendo as atividades propostas. Assim, aumentou o diálogo entre a equipe e os seguidores, pois também permitiu a discussão de temáticas relacionadas à fotografia, à fauna, ao tráfico de animais silvestres e à preservação ambiental, culminando em um resultado positivo e corroborando com Baalbaki et al. (2015), segundo os quais o Facebook constitui-se em uma ferramenta essencial para a divulgação de projetos de extensão, pois trata-se de uma das redes sociais com mais usuários cadastrados do mundo, permitindo que pessoas de diversos países tenham acesso às informações.

\footnotetext{
Disponível em: <https:// www.facebook.com/ avesdosmontes/?ref=aymt homepage_panel>.
} 


\section{CONSIDERAÇÕES FINAIS}

O Plano Nacional da Extensão Universitária cita que a educação ambiental e a sustentabilidade devem ser inseridas como componentes da atividade extensionista. Assim, compete à extensão universitária, além da contribuição fundamental à área ambiental, a articulação das açôes no âmbito das novas relaçóes entre Universidade e sociedade, não somente respondendo pelas suas demandas, mas, sobretudo, agindo efetivamente para sua transformação de forma a interferir na solução dos grandes problemas socioambientais existentes no país (BRASIL, 2012).

Por meio dos eventos propostos e realizados nos municípios mineiros de Divinópolis e Santo Antônio do Monte, foi possível observar que a metodologia utilizada e as informaçôes abordadas durante as atividades possibilitaram a sensibilização do público participante, corroborando com Sorrentino (1998) e o Programa Nacional de Educaçáo Ambiental (BRASIL, 2005), que destacam a importância das açôes de extensão como instrumento de sensibilização dos indivíduos para o enfrentamento dos problemas, possibilitandolhes refletir criticamente sobre as questôes de forma interdisciplinar, envolvendo aspectos sociais, econômicos e ecológicos.

Foi também nítido que, durante as palestras e exposiçōes fotográficas, muitos se admiraram em relação às várias espécies existentes na regiấo, na maioria das vezes, por eles desconhecidas Assim, mostraram interesse em conhecer mais sobre a diversidade da avifauna local e ainda, como seria possível contribuir para a sua preservação. Aliado a isso, foi também notório o interesse de alguns participantes sobre as técnicas e equipamentos para a fotografia de aves.

Interessante também ressaltar que as açóes alcançaram também pessoas que não participaram das atividades presenciais do evento, obtendo uma abrangência nacional e internacional através das informaçóes disponibilizadas na página criada no Facebook. Isso permitiu que o assunto fosse exibido e discutido com pessoas de outras cidades, estados e até mesmo países.

A partir desse contexto, acreditamos que as açóes extensionistas executadas pelo projeto tenham atingido os objetivos propostos, 
contribuindo significativamente para a formaçáo de sujeitos mais conscientes e éticos, com capacidade para contribuir (e serem propagadores) para uma melhor justiça socioambiental, o que certamente refletirá em maior respeito a nossa fauna e em especial às aves, diminuindo a caça, captura e engaiolamento. Consequentemente, esperamos ter ambientes mais equilibrados e justos, com melhor qualidade de vida e com mais cantos (e encantos) de aves livres.

\section{AGRADECIMENTOS}

Às instituições parceiras que, de alguma forma, contribuíram para a realização do projeto, em especial as empresas parceiras da rede privada, Secretarias de Educação das Prefeituras Municipais de Santo Antônio do Monte e Divinópolis; ONG Ecoavis; Instituto Estadual de Florestas (IEF); Programa Institucional de Bolsas de Iniciação à Docência (PIBID/UEMG); Programa de Apoio à Extensão da Universidade do Estado de Minas Gerais (PAEx/UEMG), que disponibilizou bolsa para estudante de graduação. Em especial, aos membros do grupo "Observadores de aves de Santo Antônio do Monte" - Luiz Henrique Santos; Paulo Couto; Tiago Oliveira; Wagner Rodrigues e Willian Silveira - sem os quais seria impossível a realização do projeto.

\section{REFERÊNCIAS}

BAALBAKI, C. F. et al. O projeto de extensão e suas formas de comunicação com a comunidade externa. Revista Conexáo UEPG, Ponta Grossa, v. 11, n. 3, p. 342-355, 2015.

BARBOSA, A. D.; MARTINS, N.R.S.; MAGALHÃES, D. F. Zoonoses e saúde pública: riscos da proximidade humana com a fauna silvestre. Ciência Veterinária nos Trópicos, Recife, v. 14, n. 1-2-3, p. 1-9, 2011.

BARTHES, R. A câmara clara: nota sobre fotografia. Tradução de Júlio Castañon Guimarães. Rio de Janeiro: Nova Fronteira, 1984. $190 \mathrm{p}$.

BEHLING, G. M.; ISLAS, C. A. Extensão universitária, educação 
ambiental e ludicidade na preservação de animais silvestres. Revista Conexáo UEPG, Ponta Grossa, v. 10, n. 1, p. 128-139, 2014.

BRASIL. Decreto-lei no 6.514, de 22 de julho de 2008. Dispóe sobre as infraçóes e sançóes administrativas ao meio ambiente, estabelece o processo administrativo federal para apuração destas infraçóes, e dá outras providências. Diário Oficial da Uniáo, Brasília, DF, 23 jul. 1998.

. Lei no 9.605, de 12 de fevereiro de 1998. Dispóe sobre as sançôes penais e administrativas derivadas de condutas e atividades lesivas ao meio ambiente, e dá outras providências. Diário Oficial da União, Brasília, DF, 12 fev. 1998.

. Política Nacional de Extensão Universitária. 2012. Disponível em <http://proex.ufsc.br/files/2016/04/Pol\%C3\%ADticaNacional-de-Extens\%C3\%A3o-Universit\%C3\%A1ria-e-book.pdf>. Acesso em: 15 jan. 2018.

Programa Nacional de Educaçáo Ambiental - PRONEA. Lei no 9.795, de 27 de abril de 1999. Ministério do Meio Ambiente, Diretoria de Educação Ambiental; Ministério da Educação. Coordenação Geral de Educação Ambiental. 3. Ed. Brasília: Ministério do Meio Ambiente, 2005.

CARVALHO, V. P. O lúdico no processo de ensino-aprendizagem na educação infantil: tecendo saberes/fazeres na inclusão escolar. 2011. Monografia (Especialização em Desenvolvimento Humano) - Universidade de Brasília, Brasília, 2011.

GABRIEL, M. Marketing na era digital. São Paulo: Novatec Editora, 2010. 424 p.

GIOVANINI, D. I Relatório Nacional Sobre o Tráfico de Fauna Silvestre. Brasília: Rede Nacional de Combate ao Tráfico de Animais - RENCTAS, 2002. 108 p.

GONÇALVES, M. L. Q.; REGALADO, L. B. A relação entre o homem e o animal silvestre como uma questáo de educaçáo ambiental. Fórum Ambiental da Alta Paulista, v. 2, p. 309-330, 2007.

HAMADA, H. H. Tráfico de animais silvestres: uma abordagem analítica do fenômeno criminal no Estado de Minas Gerais. O Alferes, 
Belo Horizonte, v. 19, n. 56, p. 59-82, 2004.

HERNANDEZ, E. F. T.; CARVALHO, M. S. O tráfico de animais silvestres no Estado do Paraná. Acta Scientiarum Human and Social Sciences, Maringá, v. 28, n. 2, p. 257-266, 2006. doi: https://doi. org/10.4025/actascihumansoc.v28i2.168.

IBGE - Instituto Brasileiro de Geografia e Estatística. Cidades. Disponível em: <https://cidades.ibge.gov.br/>. Acesso em: 18 mar. 2018.

MARINI, M. A.; GARCIA, F. I. Conservação de Aves no Brasil. Megadiversidade, Belo Horizonte, v. 1, n. 1, p. 95-102, jul. 2005.

NUNES, P. B.; BARRETO, A. S.; FRANCO, E. Z. Subsídios à ação fiscalizatória no combate ao tráfico de aves silvestres e exóticas em Santa Catarina. Ornithologia, Cabedelo, v. 5, n.1, p. 26-33, maio 2012.

PEREIRA, G. A.; BRITO, M. T. Diversidade de aves silvestres comercializadas nas feiras livres da Região Metropolitana de Recife, Pernambuco. Atualidades Ornitológicas, Ivaiporã, n. 126, p. 14-20, jul-ago. 2005.

PROHNII, S. S. et al. Bioética ambiental: refletindo a questão ética envolvida na manutenção de animais cativos em zoológicos. Disponível em: <http://jorneb.pucpr.br/wpcontent/ uploads/sites. pdf>. Acesso em 10 mar. 2017.

ROCHA, A. P. O. A educaçáo ambiental no contexto escolar como elemento indispensável para transformaçáo da consciência ambiental. 2010. 45f. Monografia (Graduação em Pedagogia) - Instituto Superior de Educaçáo da Faculdade Alfredo Nasser, Aparecida de Goiânia, 2010. Disponível em: <http://www.unifan. edu.br/files/pesquisa>. Acesso em: 2 mar. 2017.

SICK, H. Ornitologia Brasileira. Rio de Janeiro: Nova Fronteira, 1997. $912 \mathrm{p}$.

SILVEIRA, L. F.; MÉNDEZ A. C. Caracterização das formas brasileiras do gênero Sicalis (Passeriformes, Emberizidae). Atualidades Ornitológicas, Ivaiporã, n. 90, p. 6-8, 1999. 
SORRENTINO, M. De Tbilisi a Tessaloniki, a educação ambiental no Brasil. In: JACOBI, P. et al. (Org.). Educaçáo, meio ambiente e cidadania: reflexôes e experiências. São Paulo: SMA, 1998. p. 27-32.

VIDOLIN, G. P. et al. Programa estadual de manejo de fauna silvestre apreendida: estado do Paraná, Brasil. Cadernos de biodiversidade, v. 4, n. 2, p. 37-49, dez. 2004.

Submetido em 5 de fevereiro de 2018.

Aprovado em 20 de abril de 2018. 